\title{
Recent applications of cell-penetrating peptide guidance of nanosystems in breast and prostate cancer (Review)
}

\author{
SAMUEL LONGORIA-GARCÍA ${ }^{1}$, \\ CELIA NOHEMI SÁNCHEZ-DOMÍNGUEZ ${ }^{1}$ and HUGO LEONID GALLARDO-BLANCO ${ }^{2}$
}

\author{
${ }^{1}$ Department of Biochemistry and Molecular Medicine, School of Medicine, Autonomous University of Nuevo Leon; \\ ${ }^{2}$ Department of Genetics, University Hospital 'José Eleuterio González', \\ Autonomous University of Nuevo Leon, Monterrey, Nuevo León 64460, Mexico
}

Received November 17, 2021; Accepted January 17, 2022

DOI: $10.3892 / 01.2022 .13223$

\begin{abstract}
Cell-penetrating peptides (CPPs) are small peptides from natural sources or designed from other protein sequences that can penetrate cell membranes. This property has been used in biomedicine to add them to biomolecules to improve their capacity for cell internalization and as a guidance tool for specific cell types. CPPs have been shown to enhance cellular uptake in vitro and in vivo, improving the efficacy of anticancer drugs such as doxorubicin and paclitaxel, while also limiting their cytotoxic effects on healthy cells and tissues. The current study reviews the internalization and major therapeutic results achieved from the functionalization of nanosystems with CPPs for guidance into breast and prostate cancer cells in vitro and in vivo. In addition, the practical results obtained are specifically discussed for use as a starting point for scientists looking to begin research in this field.
\end{abstract}

\section{Contents}

1. Introduction

2. Standard cancer therapies vs. alternative treatments

3. Strategies for site-directed cancer therapy using NSs

4. Improving NS properties

5. Guided delivery of NSs by CPPs

6. CPPs coupled to NSs for BC

7. CPPs coupled to NSs for PC

8. Conclusions and outlook

Correspondence to: Dr Hugo Leonid Gallardo-Blanco, Department of Genetics, University Hospital 'José Eleuterio González', Autonomous University of Nuevo Leon, 235 José Eleuterio González, Mitras Centro, Monterrey, Nuevo León 64460, Mexico

E-mail: hugo.gallardobl@uanl.edu.mx

Key words: nanosystems, nanoparticles, cell-penetrating peptides, breast cancer, prostate cancer

\section{Introduction}

Cancer is a common cause of death worldwide; its two essential characteristics are the loss of cell growth control, which leads to tumor formation, and the invasion of other tissues through metastasis. In addition, dissemination through blood or lymphatic vessels leads to secondary tumors. It has been estimated that $\sim 18.1$ million new cases and 9.6 million deaths were related to this disease in 2018. In women, the second most common type of cancer is breast cancer (BC), with $11.6 \%$ of cases, and in men, prostate cancer (PC) is the second most common type of cancer, with $7.1 \%$ of cases (1).

Hanahan and Weinberg described six major hallmarks of cancer progression. These are sustaining proliferative signaling, evading growth suppressors, activating invasion and metastasis, enabling replicative immortality, inducing angiogenesis and resisting cell death (2). In recent years, most of the knowledge attained has been in elucidating cancer biology. Generally speaking, a single gene mutation seldom causes cancer. However, cancer can occur when a mutation falls in a key gene. These key genes can be categorized into three main groups: i) Proto-oncogenes; ii) tumor suppressor genes; and iii) DNA repair genes (3). Advances in cancer biology have identified possible molecular targets in $\mathrm{BC}$ and $\mathrm{PC}$.

$\mathrm{BC}$ is a highly heterogeneous disease with complex classification subtypes such as Luminal A, Luminal B, HER2positive and triple-negative. Most $\mathrm{BC}$ cases are invasive ductal carcinoma; however, inflammatory $\mathrm{BC}$ is also of concern due to its aggressiveness and occurrence in different patient populations (4). Similarly, PC is classified into three categories regarding its biology: i) Endocrine-driven; ii) microenvironment-dependent; and iii) tumor cell-autonomous (5). Several PC studies have demonstrated the role of the androgen receptor (AR) in its development and progression (6-10). The AR is located in the cytoplasm and, when bound with its ligand, translocates into the cell nucleus recognizing hormone response elements in regulatory genomic regions (11).

\section{Standard cancer therapies vs. alternative treatments}

The objective of cancer therapy is to keep the patient free of disease or in remission with a partial or complete decrease of 
symptoms. The most common cancer therapies are surgery, radiotherapy and chemotherapy. In addition to being local treatments, they possess several disadvantages and limitations. For example, surgery requires diagnosis at an early stage of the disease, when metastasis development is less frequent; however, overdiagnosis has increased the number of mastectomies and prostatectomies performed each year (12).

Radiotherapy is applied to $30-40 \%$ of solid tumors, alone or combined with other treatments. However, it causes genetic damage to tumor cells and surrounding healthy tissues, with severe side effects. Radiation exposure also causes inflammation and, consequently, oxidative damage. High doses cause chronic damage that interferes with the healing ability of the tissue $(12,13)$. Chemotherapy generally lacks specificity, leading to cytotoxic damage throughout the body and the development of resistance $(14,15)$. Chemotherapy and radiotherapy have been shown to cause DNA double-strand breaks, increasing the production of reactive oxygen species (ROS) and a general stress response. This damage leads to several possible outcomes besides apoptosis, such as cell cycle arrest, senescence, mitotic catastrophe, inflammatory response and fibrosis at the tissue level (16).

Targeted therapies are directed at a biochemical pathway or target molecule required for tumor survival (15). Given the limitations of conventional treatments, the term precision medicine has emerged, in which therapy is directed according to the characteristics of the cancer to be treated. This therapy includes antibodies, drugs, nucleic acids and other therapeutic molecules. However, targeted therapies could be improved using nanosystems (NSs) as carriers whose surface can be modified to include the therapeutic principle and other components to protect the NS and facilitate target cell recognition and entry.

Nanomedicine development involves several types of nanoplatforms such as metallic and polymeric nanoparticles (NPs), nanoliposomes and nanomicelles, among others (17). Additionally, stimuli-responsive drug release systems increase cytotoxicity against cancer cells (18-20). Some of these nanoplatforms, along with the most common stimuli-responsive drug release systems, are shown in Fig. 1.

\section{Strategies for site-directed cancer therapy using NSs}

One highly advantageous characteristic of NSs is their ability to be functionalized in several ways for specific guidance to cancer cells and tumors. Several guidance tools are used, such as antibodies and aptamers. Some of these strategies can be seen in Fig. 2.

Other properties rely on the nature of the NP. Polymersomes, also called polymeric vesicles, have specific features varying by polymer composition. Generally, they have high stability, adaptable physicochemical properties, an easily-modified surface and a highly adjustable permeability membrane $(21,22)$. Nanomicelles are commonly self-assembled; they can carry hydrophilic drugs, protecting them from unwanted interactions $(23,24)$.

Similarly, nanoliposomes possess a specific characteristic of carrying both hydrophobic and hydrophilic drugs due to their double lipid membrane $(25,26)$. Metallic NPs can serve as theranostics by carrying anticancer drugs and taking advantage of surface plasmon resonance for photothermal therapy and imaging $(27,28)$. On another approach, nanoliposomes were used to develop a synthetic vaccine particle carryng rapamycin (SVP-rapamycin), with the objective of inducing a tolerogenic immune profile to NPs (29).

The present review discusses one of the most common guidance tools used, known as cell-penetrating peptides (CPPs). CPPs are small peptides, usually 5 to 30 amino acids in length, that are designed from other protein sequences, have a short life and can penetrate cell membranes in a nonselective way in most cases (30). However, as will be discussed further, some cell-specific CPPs have been studied and developed. Furthermore, the definition of CPPs has been changing throughout the years since their discovery $>20$ years ago. One definition that globally encompasses all descriptions known to date is 'any peptide that can, to a measurable degree, enter the interior of living cells in cell culture, or deliver a membraneimpermeant cargo' (31). This assumption will be considered for the present review.

The first reports of CPPs were from studies related to human immunodeficiency virus (HIV) and its cellular uptake $(32,33)$. The TAT peptide, corresponding to the basic domain of HIV-1 TAT protein, was one of the first reported. Afterward, a homeodomain of the transcription factor antennapedia from Drosophila melanogaster also showed penetrating activity. This finding led to discovery of the CPP, penetratin, which corresponds to the third helix of the antennapedia homeodomain (34).

CPPs are added to molecules to improve their capacity for cell internalization (30). CPPs can deliver cargoes inside the cell through two primary mechanisms: Direct penetration and endocytosis, depending on several physicochemical properties (35). However, other reports mention some CPPs with a pore formation mechanism (31,36-39). Four major penetration models have been proposed through these mechanisms: Reverse vesicle endocytosis, direct translocation, adaptive translocation and pore formation (34). A general schematic of these models applied to NSs is presented in Fig. 3. The variety of mechanisms related to the heterogenicity of sequences of the CPPs impact their biochemical properties. Some of these properties, which must be considered when developing an NS, are shown in Table I, along with the basic classification used for most available CPPs (35). Most of the studies discussed in the present review involve cationic peptides, which are generally attributed to a direct penetration mechanism by being adsorbed onto cell surfaces due to anionic moieties $(35,40)$. Each CPP sequence discussed in the present review is included when available.

The chemical reaction for CPP binding (also known as conjugation) to the NP depends most on the NP used. Lipidbased NPs rely on terminal amino and carboxyl groups from the peptide and lipids. The conjugation reaction is performed under constant stirring in a solution that contains both the lipids and the CPP $(41,42)$. CPP conjugation to metallic NPs can be achieved by a thiol (SH)-ether bond between Cys from the CPP and a maleimide group in polyethylene glycol (PEG). Different sources of the required functional groups exist; one example is a functionalized SH-PEG and a maleimide-PEG (43). 
Delivery platforms:

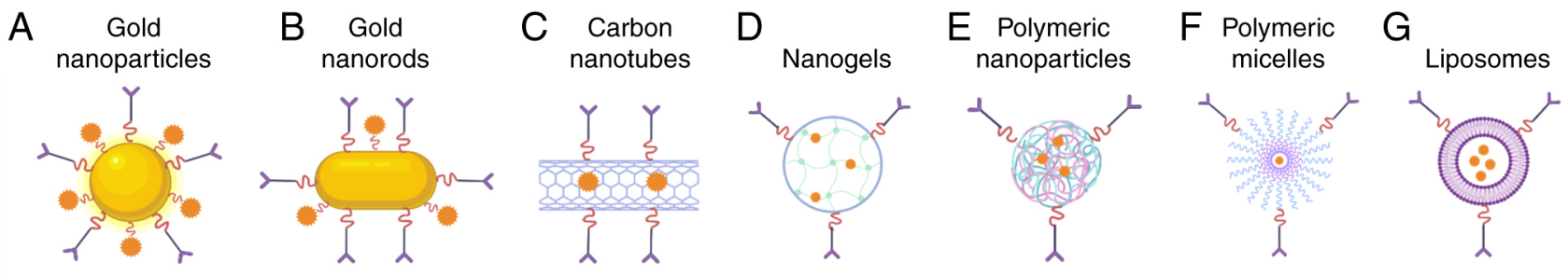

Delivery mechanism:

Stimuli-responsive drug release

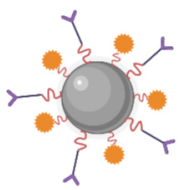

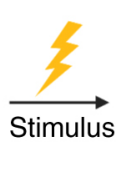

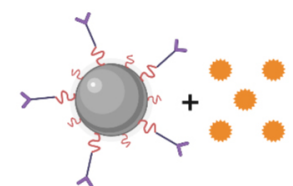

External stimuli

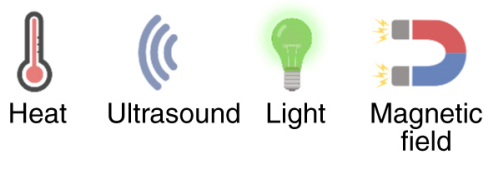

Internal stimuli

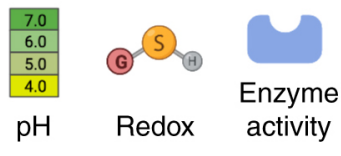

Figure 1. Common delivery nanoplatforms and stimuli-responsive drug release systems used in the treatment of several types of cancer. Stimuli-responsive drug release can be used for controlled delivery into a target tissue. However, internal stimuli have been mostly applied in metallic NPs, such as (A) gold nanoparticles and (B) gold nanorods, since their mechanism involves the activation and/or cleavage of an essential component of the nanosystem, releasing the drug. External stimuli generally have been applied in (C) carbon nanotubes, (D) nanogels, (E) polymeric NPs, (F) polymeric micelles and (G) liposomes, since their mechanism mostly involves the dissolution or disappearance of the NP. Examples of external stimuli are shown. Figure created with BioRender.com. NP, nanoparticle.
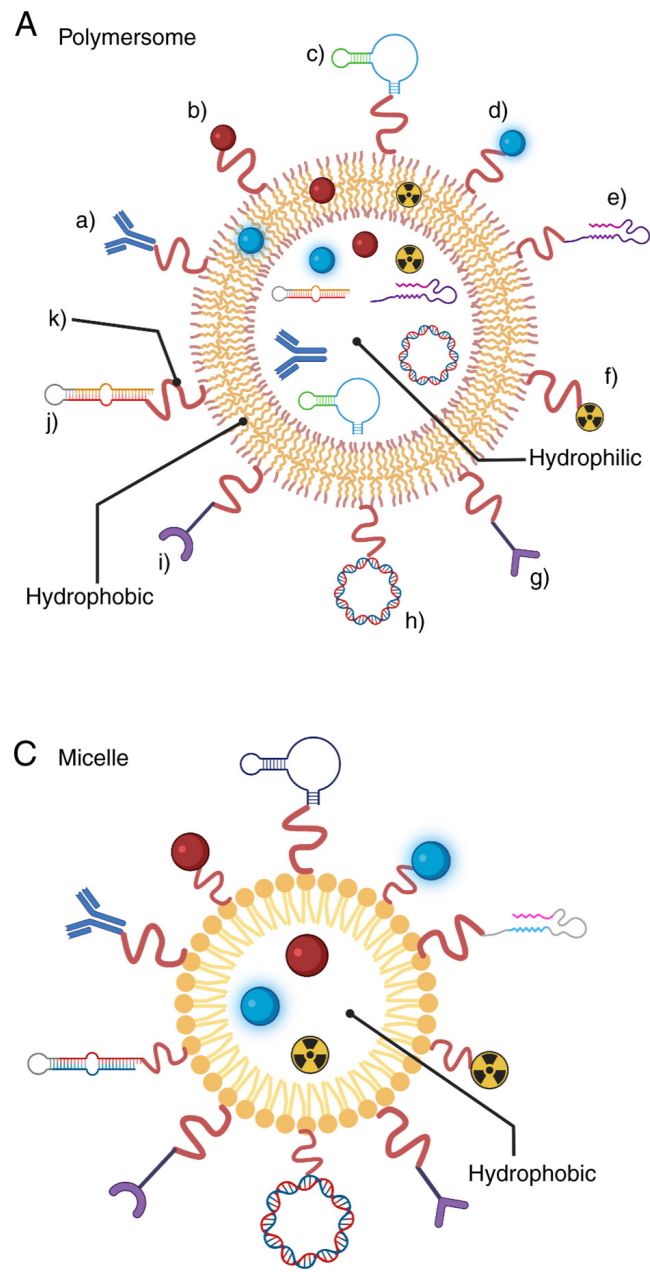

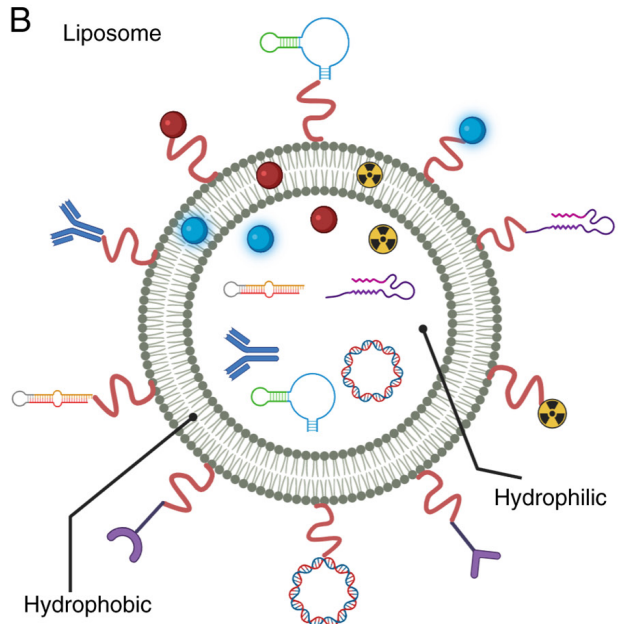

D Metallic nanoparticle

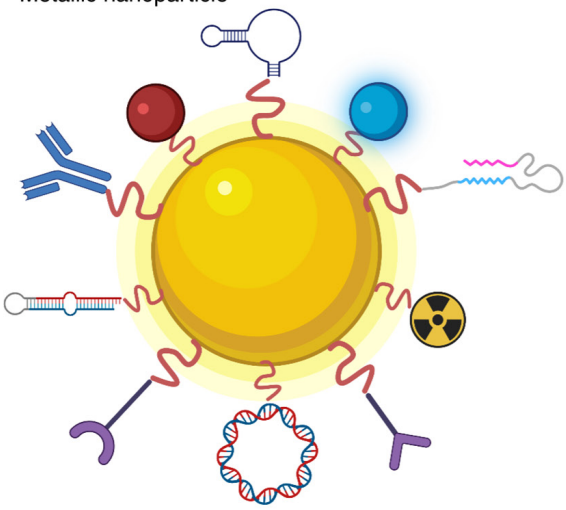

Figure 2. Functionalization strategies for specific site-direction of NPs. Antibodies, targeting ligand and aptamer guidance have been used for highly specific delivery into a particular cell type. Fluorescent dyes and radioligands have been used for diagnostic purposes. Drug, DNA vector and pre-miRNA coupling have been studied for therapeutic purposes. CPPs and enzymes have been shown to increase cell uptake. A linker chain is required for coupling to the NP surface. The nature of (A) polymersomes, (B) liposomes and (C) micelles allows them to be used as a vehicle for delivering hydrophobic and/or hydrophilic anticancer agents, among others. The nature of (D) metallic nanoparticles allows them to be used as theranostics for both drug delivery and imaging applications. Figure created with BioRender.com. Key: a), antibodies; b), drug; c), targeting ligand; d), fluorescent dye; e), CPP; f), radioligand; g), aptamer; h), DNA vector; i), enzyme; j), pre-miRNA; k), linker chain. NP, nanoparticle; CPP, cell-penetrating peptide; miRNA, microRNA. 


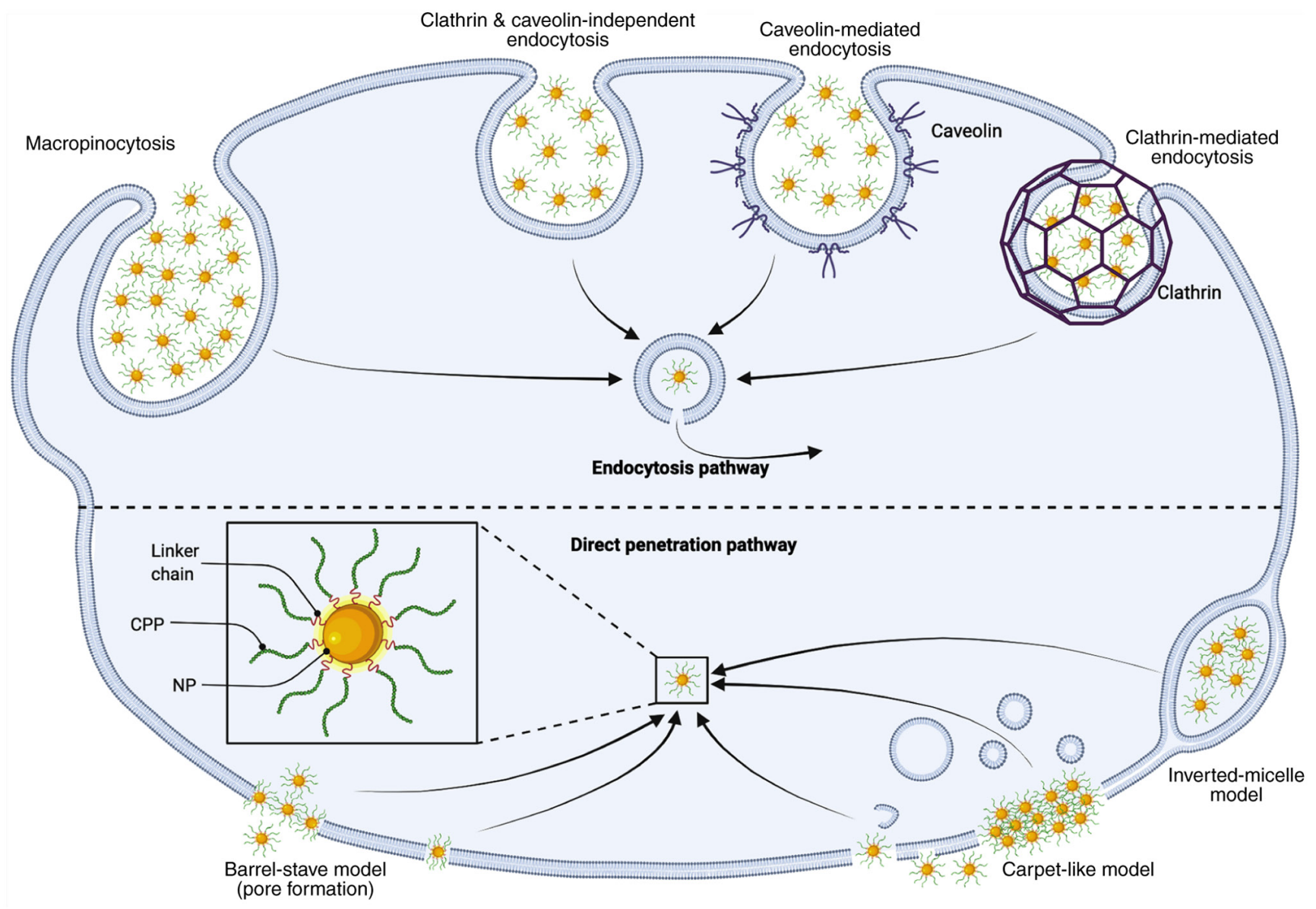

Figure 3. Previously proposed models for CPP internalization mechanisms when coupled to NPs. These mechanisms can be divided into two major pathways: Endocytosis and direct penetration. Endocytosis is an energy-dependent process that may be further subclassified as macropinocytosis, clathrin- and caveolin-independent endocytosis, caveolin-mediated endocytosis and clathrin-mediated endocytosis. Endocytosis is usually related to cell membrane receptor internalization. The direct penetration pathway is an energy independent process that involves the interaction of positively charged CPPs with the negatively charged cell membrane. This interaction can lead to pore formation or membrane destabilization (carpet-like model and inverted-micelle model), which will lead to CPP-NS penetration. Figure created with BioRender.com. NP, nanoparticle; CPP, cell-penetrating peptide; NS, nanosystem.

\section{Improving NS properties}

One of the challenges in the construction of NSs is to improve stability, biocompatibility and cell penetration. For instance, one strategy for inducing apoptosis and inhibiting tumor cell proliferation involves using small interfering RNAs (siRNAs) (44-46). The main limitation of this technology is that when administered in the systemic circulation, the siRNA faces two main problems. The first is its limited cellpenetrating properties, and the second, its rapid degradation by circulating ribonucleases. Incorporating polymers such as PEG and hyaluronic acid (HA) contributes stealthiness against the immune system of the host, and improves biocompatibility and biodegradability (47-50). In addition, cationic polymers such as chitosan are implemented when the therapeutic agent is RNA, protecting it against degradation and further cell internalization (51).

\section{Guided delivery of NSs by CPPs}

The most common uses of CPPs include improving cancer treatment with drugs and gene therapies, among others. In vitro and in vivo experiments have been conducted to improve cell penetration, stability, viability and drug cytotoxicity, and to reduce tumor size. However, a valid concern raised by several researchers is the lack of specificity of some CPPs, which could lead to drug delivery to cells in healthy tissues. Some modifications, such as antibody or antibody fragments and aptamers, could be incorporated into the NS for specific targeting. Other researchers have developed chimeric CPPs that specifically target cancer cells (52-54). Next, the present review discusses some of the NSs coupled to CPP for BC and PC.

\section{CPPs coupled to NSs for BC}

\section{NSs coupled to CPP to guide drug release in $B C$}

Doxorubicin (DOX). DOX is commonly used to treat various types of cancer, including BC. However, despite wide use, it has well known undesirable side effects, such as cardiotoxicity (55). Various types of CPP have been coupled to a variety of NSs, including liposomes, gold, dendrigraft, iron oxides and polymeric structures. These NSs carrying DOX and/or other anticancer drugs have been tested in vivo and in vitro to improve delivery and reduce side effects. Below, the present review briefly describes some of the NSs that have been coupled to CPPs. 
Table I. Examples of CPPs, their classification and other biochemical characteristics.

\begin{tabular}{|c|c|c|c|c|}
\hline Classification & CPP name & $\begin{array}{l}\text { Sequence } \\
\text { length, aa }\end{array}$ & $\begin{array}{c}\text { Molecular } \\
\text { weight, kDa }\end{array}$ & Isoelectric point \\
\hline \multirow[t]{10}{*}{ Amphipathic } & p28 & 28 & 2.91 & 3.49 \\
\hline & VT5 & 26 & 2.60 & 6.17 \\
\hline & Pep-1 & 21 & 2.84 & 10.48 \\
\hline & $\mathrm{BPrPr}$ & 28 & 3.19 & 10.65 \\
\hline & Transportan & 27 & 2.84 & 10.75 \\
\hline & MAP & 18 & 1.87 & 11.27 \\
\hline & MPG & 27 & 2.80 & 11.74 \\
\hline & ARF & 22 & 2.65 & 12.49 \\
\hline & $\mathrm{pVEC}$ & 18 & 2.21 & 12.59 \\
\hline & Bac7 & 24 & 2.93 & 13.00 \\
\hline \multirow[t]{3}{*}{ Hydrophobic } & Pep-7 & 15 & 1.80 & 3.28 \\
\hline & PFVYLI & 6 & 0.75 & 5.54 \\
\hline & C105Y & 17 & 1.99 & 8.05 \\
\hline \multirow[t]{5}{*}{ Cationic } & DPV1047 & 19 & 2.31 & 12.29 \\
\hline & Penetratin, pAntp & 16 & 2.24 & 12.44 \\
\hline & HIV-1 TAT protein & 13 & 1.80 & 3.28 \\
\hline & HIV-1 TAT protein 9 aa & 9 & 1.34 & 12.80 \\
\hline & Polyarginines $\left(\mathrm{R}_{7}-\mathrm{R}_{9}\right)$ & Variable, 7-9 & Variable, $1.10-1.40$ & Variable, $12.78-12.90$ \\
\hline
\end{tabular}

Table created using Geneious Prime 2021.2.2. (https://www.geneious.com). CPP, cell-penetrating peptide; HIV, human immunodeficiency virus.

CPP PVF (PFVYLI). Hydrophobic CPP PVF coupled to a 100-nm liposome was evaluated in MCF-7, MDA-MB-435S, MCF-7/Adr (Adriamycin-resistant human mammary adenocarcinoma) and 4T1 murine BC carcinoma cell lines. Even when the cell survival rate was higher in cells treated with the NS in vivo, the NS decreased the tumor weight up to $0.4 \mathrm{~g}$ compared with the control $(0.9 \mathrm{~g})$ and free DOX $(0.7 \mathrm{~g})$, while keeping the mice at a healthier weight compared with the free DOX-treated mice (41).

$H I V$-derived TAT CPP (YGRKKRRQRRRTAT). With the ability to permeate the blood-brain barrier, the HIV-derived TAT CPP was evaluated in MDA-MB-231 cell lines and metastatic in vivo tumors using gold NPs coupled with PEG as the carrying vehicle for DOX. In vivo cell uptake increased 4.8-fold compared with that of the control, while DOX half maximal inhibitory concentration $\left(\mathrm{IC}_{50}\right)$ decreased $80 \%$ compared with that of free DOX. Furthermore, no significant adverse effects were found when the DOX dose of the NS ranged from 1 to $5 \mu \mathrm{g}$. However, at 10 and $15 \mu \mathrm{g}$ DOX, the mice exhibited significant weight loss, which a common side effect of this drug. Also, the development of ascites and peripheral edema was found in the mice, which a relatively common adverse effect of DOX metabolism. These results suggest further targeting with this NS should be achieved before moving into clinical trials (43).

TAT peptide fragment ( $R K K R R R Q R C$ ). A gold nanostar coupled with mesoporous silica (MS), TAT fragment and the photosensitizer drug protoporphyrin IX was used as a theranostic system. Also, Raman detection for diagnostics, photodynamic therapy (PDT) and cytotoxicity were evaluated in the BT-549 cell line. Through Raman imaging, it was determined that TAT CPP activity allowed cell penetration while maintaining cell viability, although once PDT was applied, the cell viability was decreased (56). A similar study used an NS containing TAT and gold NPs along with anti-HER2 antibody for increased specificity and surface-enhanced Raman spectroscopy, which was assessed for DOX release rate into SK-BR-3 cells. After $24 \mathrm{~h}$, in vitro cell viability was decreased by $39.48 \%$ compared with that of the control (57). Another study designed a synthetic peptide containing TAT, L-lysine residues, fusogenic GALA peptide and cell targeting peptide (DMPGTVLP) with stearic acid to improve condensation and stability to a dioleoylphosphatidylethanolamine (DOPE)-based nanoliposome. This NS was evaluated against MCF-7 cells delivering an siRNA targeting BCL2 mRNA. The chimeric peptide used in this NS increased cell uptake, and BCL2 silencing was decreased by $\sim 80 \%$. However, cell viability was decreased by only $20 \%$ (58).

Angiopep-2 CPP (TFFYGGSRGKRNNFKTEEY). The size of the NS directly impacts tumor accumulation and diffusion abilities. Keeping this in mind, researchers developed an NS that could be decreased in size by the action of metalloproteinase-2, while keeping high specificity for triple-negative BC (TNBC). Gelatin and dendrigraft polylysine were used as a carrying vehicle and stabilization agent, while DOX was used as the anticancer agent in 4T1 cells. As expected, in vitro cell uptake was increased from 15 to $40 \%$, which translated into a higher inhibition rate. In vivo, there was an $\sim 3$-fold decrease in tumor volume and a 4-fold decrease in tumor weight compared 
with that for free DOX treatment. Furthermore, no difference in mouse bodyweight was reported, suggesting the relative safety of this NS (59).

Arginine-rich amphiphile CPP (lauryl-PPPPRRRR). A nanoliposome-based system carrying the arginine-rich amphiphile CPP and DOX or paclitaxel (PTX) was tested in MCF-7 cells. After $3 \mathrm{~h}$, cell uptake had increased 5-fold with rhodamine B (a hydrophilic dye) and 30\% with Nile red (a hydrophobic dye) to show this dual amphiphile activity. The drug uptake and effectiveness of the liposome improved with the NS compared with the use of free drugs. In vitro, cancer cell viability was decreased by 50 and $25 \%$ in the CPP-DOX-NS and NS-PTX groups, respectively (60). These results show a significant difference between NSs with CPPs and those that do not have them coupled.

QLPVM CPP peptide. The QLPVM CPP was attached to a 1,2-distearoyl-sn-glycero-3-phosphorylethanolamine (DSPE)PEG-based nanoliposome carrying tamoxifen (TAM) and DOX, evaluated in MCF-7 cell tumor-bearing mouse models. In vitro cell viability was dose-dependent for the NS. However, cell viability was lower than that in the NS-free TAM and NS-free DOX groups. In vivo tumor inhibition with the combined NS showed the best results. In a synergistic effect, tumor volume decreased 7-fold compared with that of the control, with similar results in tumor weight and no noticeable bodyweight loss or cardiac toxicity (61).

Chimeric $R_{8} C P P\left(A V P I R_{8}\right)$. A disadvantage of drug therapy is the existence of drug-resistant tumors. Thus, the chimeric R8 $\mathrm{CPP}$ was fused with an apoptotic peptide to create a co-delivery nanocomplex in MCF7-DOX resistant cells. The nanocomplex consisted of binding several wild-type p53 proteins, chimeric CPPs and p53 DNA. Assembly was enabled by preparing a mixture of these components and incubating them at $37^{\circ} \mathrm{C}$ for $30 \mathrm{~min}$ to allow the formation of the nanocomplex. There was a 36-fold in vitro increase in apoptosis in the synergistic NS compared with that in free DOX, leading to a $97.9 \%$ decrease in cell viability. In vivo, there was a significant tumor volume and weight decrease when the mice were treated with the NS. Tumor volume decreased $\sim 10$-fold, while tumor weight was 9-fold lower at 21 days post-injection (62).

$R_{7} C P P$ (RRRRRRR). The $\mathrm{R}_{7} \mathrm{CPP}$ was coupled in a polylactic-co-glycolic acid-PEG polymer with folic acid and the cell-cycle anticancer agent, vincristine sulfate (VCR). Cell uptake mediated by $\mathrm{R}_{7}$ was not significantly different from cell uptake mediated by folic acid and its receptors. However, cell viability was decreased to $30 \%$ when $5 \mathrm{nM}$ VCR was added, compared with $60 \%$ cell viability without VCR. These results were further confirmed by determining an increase in MCF-7 cell percentage in the $\mathrm{G} 2 / \mathrm{M}$ arrest phase from $12.28 \pm 1.74 \%$ to $>33 \%$ (63).

$R_{9} C P P(R R R R R R R R R)$. A DSPE-PEG-based nanoliposome coupled with $\mathrm{R}_{9}$ was developed to deliver cabazitaxel in the $4 \mathrm{~T} 1$ cell line and murine models. Cell uptake was increased 1.78 -fold after $8 \mathrm{~h}$ of exposure compared with the control. In vitro cytotoxicity was enhanced 223 -fold to $0.03 \mu \mathrm{g} / \mathrm{ml}$ due to NS activity. In vivo, the NS localization in the lymph nodes was reported to increase 1.73 -fold at $24 \mathrm{~h}$ post-injection. This finding demonstrates a penetrating activity with long retention times. Also, primary tumor growth decreased $75.3 \%$, while tumor inhibition in the lymph nodes was reported at $89.1 \%$, showing that this NS can inhibit metastasis. The size of this NS was $13 \mathrm{~nm}$; NSs with sizes $<30 \mathrm{~nm}$ have been reported to have better access to lymph nodes (64-66).

$i R G D$ peptide (CRGDK/RGPD/EC). Vesicles extracted from red blood cell membranes and coupled to iRGD peptide were used as biological NSs carrying PTX. In vitro cell uptake in 4T1 cells was higher in the NS compared with that in the control. However, in vitro cell viability was similar compared with that of free PTX. In vivo, the NS decreased tumor growth to $8.5 \%, 5.6$-fold less compared to the control (67). In a similar study, the iRGD CPP coupled to iron oxide nanoworms was used as an NS to inhibit or lower BC metastasis to the brain, targeting MDA-MB-231 and $4 \mathrm{~T} 1$ xenografts in $231 \mathrm{Br}$ and 4T1-BR5 mouse models. Brain imaging showed that 30 days post-injection, the number of tumors was decreased by $60 \%$, and their size had decreased 5-fold compared with the controls. However, researchers found a tight window of 12 days for this metastasis decrease (68).

Pentapeptide CALNN CPP (CALNN). The pentapeptide CALNN CPP coupled with gold NPs was used to deliver linalool (a monoterpenoid derived from plants) and evaluate its anticancer activity in MCF-7 cells. In vitro cytotoxicity was reported at $>80 \%$ after $48 \mathrm{~h}$ of treatment, while clonogenicity was inhibited. In vivo, the NS conferred no statistical change in mouse health, suggesting the safety of the NS for further study. Unfortunately, the study did not include in vivo anticancer activity assays (69).

\section{CF CPP (CREKA-CN2-CKDEPQRRSARLSAKPAPPKPEPK}

$P K K A P A K K-N H 2)$. CREKA, a linear pentapeptide designed to bind to fibrous protein in the tumor microenvironment, was fused to the CF peptide (a CPP for nucleus translocation) using a polylactic acid-based NS as the vehicle. This NS was designed for targeted delivery of the anticancer drug erlotinib into MDA-MB-231 cell lines to combat drug resistance in TNBC. Cell uptake was increased 2.3-fold when the $\mathrm{pH}$ of the assay was similar to that of the tumor microenvironment. In vitro cell viability decreased $<20 \%$ in the $\mathrm{pH}$ simulating the tumor microenvironment, compared with that in the physiological $\mathrm{pH}$, which maintained $50 \%$ viability. In vivo, a 2.8 -fold tumor decrease was observed in mice treated with the NS, while their body weight was maintained, suggesting an effective method for TNBC tumor treatment that lacked adverse effects (70).

tLyP-1 CPP (CGNKRTRG). The tLyP-1 CPP, which specifically targets tumors, was used to develop an NS targeting MDA-MD-231 cells. The polymeric NPs consisted of HA and D- $\alpha$ tocopheryl succinate as a vehicle. The NS carried the anticancer drug docetaxel. Cell uptake compared with that of the control increased 2.36-fold, while in vitro, cell cytotoxicity was higher in the NS with tLyP-1. In vivo tumor weight decreased 3.5-fold compared to the control (71). 
PEGA-pVEC CPP (CPGPEGAGC-LLIILRRRIRKQ $A H A H S K)$. The PEGA-pVEC CPP that targets BC cells and tumors was coupled to an NS of colloidal MS as a vehicle for the anticancer agent epigallocatechin-3-gallate (EGCG) in MCF-7 cells. In vitro cell inhibition reached $100 \%$ at a $100 \mu \mathrm{g} / \mathrm{ml}$ concentration. In vivo tumor inhibition of up to $89.66 \%$ was reported compared with $69.9 \%$ in the control group in murine models (72). In a similar study, PEGA-pVEC was used to develop an MS and HA NS as a carrying vehicle for DOX and an siRNA directed against the BC overexpressed connective tissue growth factor gene. The NS was tested in drug-resistant MDA-MB-231 cells. In vitro inhibition increased from 59 to $80 \%$ compared with the control. In vivo, the tumor inhibition increased up to $60 \%$ compared with the control (73). A similar study developed a self-aggregating nano-gel based on protamine aggregates carrying EGCG as an anticancer agent to MDA-MB-231 cells and xenografts. In vitro, there was a 15 -fold increase in cytotoxicity compared with the control, while in vivo tumor inhibition was $80 \%$ compared with the control (74).

Chimeric arginine-glycine-aspartate $C P P(R G D$ and $R G E$ $R P P R)$. The chimeric arginine-glycine-aspartate CPP was evaluated in MDA-MB-231 cells using gambogic acid (GA) as an anticancer agent and nanostructured lipid nanocarriers. When cells were treated with a $2 \mu \mathrm{g} / \mathrm{ml}$ concentration, in vitro cell viability was decreased to $<20 \%$ compared with that of the control. However, the best inhibition rate and tumor size decrease were achieved with the NS carrying RGERPPR alone, suggesting that only one CPP can benefit a single NS (75).

$C P P$ coupled to NSs for gene and recombinant therapy in $B C$ gH625 CPP (HGLASTLTRWAHYNALIRAF). An NS, delivering a novel, non-disclosed siRNA consisting of superparamagnetic iron oxide NPs (SPIONs) functionalized with PEG, and cationic polymers, such as chitosan and L-arginine with CPP gH625, was designed and evaluated against the MDA-MB-231 cancer cell line. After $4 \mathrm{~h}$ of exposure, the NS penetrated the cells aided by the gH625 peptide, and the MDA-MB-231 cancer cell line genes were downregulated due to the interference mechanism of the siRNA. At $72 \mathrm{~h}$, there was cell growth inhibition of nearly $80 \%$ (51). gH625 in an NS SPION couple was also tested in MDA-MB-231 cells as a theranostic system. Cell uptake increased 3-fold in the NS compared with that in the control assay (76).

$R_{9} C P P$ (RRRRRRRRR). The Twist gene is a transcription factor for an epithelial-mesenchymal transition that is heavily involved in the metastatic activity of tumors. Therefore, a nano-corona NS consisting of a DOPE NP carrying an siRNA against the Twist gene, the $\mathrm{R}_{9}$ for tumor penetration, and coated with human serum albumin for immune system camouflage, was designed and evaluated in 4T1 cells. The nano-coronas were labeled with IR-780 dye for combination therapy: Twist gene silencing and tumor growth inhibition using photothermal therapy for thermal ablation. Cell uptake indicated a higher NS translocation in the cytoplasm after $24 \mathrm{~h}$ of incubation; the cell migration rate decreased up to $66 \%$. The cell viability index was decreased by $90 \%$ when treated by photothermal therapy. In vivo experiments showed the ability of the NS to penetrate tumors; tumor inhibition progression was $83.6 \%$ and metastasis inhibition was $92.2 \%$ after 13 days of combination therapy (77).

TAT protein basic domain-derived CPP (RKKRRQRRR-Cys). This CPP was used to develop a lipid-based nanobubble system carrying an siRNA against an epidermal growth factor. The main objective was to evaluate the NS when applying ultrasound irradiation inside tumor cells to enhance the siRNA anticancer activity targeting MDA-MB-231 cells. Cell inhibition was increased from 48 to $72 \mathrm{~h}$, while in vivo tumor growth was decreased by $42.08 \%$ (78).

Chimeric Tat-Mu CPP (YGRKKRRQRRRMRRAHHRRRR $A S H R R M R G G)$. The fusion of a HER2 antibody mimeticaffibody and CPP Tat-Mu was used to deliver an anti-tissue factor using an shRNA. The NS was a cationic N,N-di-nhexadecyl-N,N-dihydroxy ethyl ammonium chloride-based nanoliposome used as a vehicle to MDA-MB-231 cells and xenografts. In vitro, cell uptake increased 7-fold compared with that of the control, while there was a significant tumor size decrease, to $<10 \%$ of the original size, in vivo (79).

Lin TT1 CPP (AKRGARSTA). The TT1 CPP has specificity against $\mathrm{p} 32$, a mitochondrial essential tumor regulator protein. Iron oxide NPs were the vehicle for the TT1 CPP fused with the proapoptotic peptide [D(KLAKLAK)2] (inducing apoptosis through the activation of caspase-3) and tested in MCF10CA1a and $4 \mathrm{~T} 1$ cell lines. In vitro cell uptake increased 4 -fold, while a tumor size decrease of $50 \%$ was observed in vivo (80). Another study consisted of a cholesterol-based nano-micelle carrying TT1 plus two anticancer components, siRNA targeting PDL-1 and indoleamine 2,3-dioxygenase inhibitor (1-methyl tryptophan), that led to the activation of cytotoxic $\mathrm{T}$ lymphocytes against the $4 \mathrm{~T} 1$ cell line. After $4 \mathrm{~h}$, cell uptake was 16.3 -fold higher than that of the control assay (81).

Penetratin-derived CPP (CKRRMKWKK). Ephrin type-A receptor 2 (EphA2) is a transmembrane protein whose overexpression has been linked to carcinogenesis, metastasis and a poor clinical prognosis. The YSA peptide, an ephrin mimetic bound with EphA2, was fused with a penetratin-derived CPP. DSPE-PEG nanobubbles were used as the vehicle for an anti-Myc siRNA acting as an anticancer agent. The in vitro cell uptake was higher with this NS treatment. In vivo tumor growth inhibition after 24 days of treatment was decreased to $31.2 \%$ compared to the control, while no significant body weight loss was found in the mice. The NPs with YSA peptides improve therapeutic effects in vivo (82).

$u$ CendR CPP (RPARSGRSAGGSVA). A urokinase activatable CPP was developed to ensure tumor specificity for in vivo targeting of 4T1 cell tumors in murine models. In addition, silver NPs were coated with PEGylated neutravidin as a vehicle and for immune system stealthiness. However, in vivo distribution was determined only in tumor tissue, without fluorescence in healthy tissue (83).

Reversibly activatable CPP (RACPP). The difference in $\mathrm{pH}$ between the tumor microenvironment and the healthy 
extracellular matrix has been exploited along with CPPs to improve the specificity of the NS. Nanopolymer micelles masked with PEG-lactic acid were used as a vehicle for the RACPP, containing a pH-sensitive sequence, and PTX as an anticancer drug targeting 4T1 cells and 4T1-BALB/c tumor xenografts models. Cell uptake was increased 3-fold, while in vitro IC50 was decreased from 1.595 to $1.035 \mu \mathrm{g} / \mathrm{ml}$. In vivo, tumor size decreased by $\sim 50 \%$ at 16 days post-injection, while the mouse survival rate increased 1.5-fold (20).

MAP CPP (KLALKLALKALKAALKLAY). In another case, the $\mathrm{pH}$-sensitive MAP CPP was used with the highly $\mathrm{pH}$-sensitive histidine-glutamate (HE) oligopeptide (HEHEHEHEH EHEHEHEHEHE) coupled to glutathione-S-transferase acting as a cargo protein. The delivery activity was measured in MDA-MB-231 cells and xenografts through fluorescence imaging. At an acidic $\mathrm{pH}$ simulating the tumor microenvironment, there was a 3-fold increase of fluorescence in vitro. In vivo results showed that at $6 \mathrm{~h}$ post-injection in mice, the system was localized mainly around the xenograft tumor. These results further show the advantage of using the $\mathrm{pH}$ of the tumor microenvironment for intelligent drug delivery systems (84).

$N G R$ chimeric CPP (NGR-CKRRMKWKK). Using a different approach, a thermosensitive NS was developed using a heatactivatable CPP after mild thermal stimulus at temperatures ranging from 37 to $42^{\circ} \mathrm{C}$, which facilitates drug delivery. The NS consisted of a nanoliposome that immediately encapsulated drugs in heating tissue or organs. These were coupled with a penetratin-derived CPP, the NGR peptide and DOX as the anticancer agent against MCF-7. In vitro cellular uptake was increased 5-fold compared with the control, while in vitro cytotoxicity of the preheated NS showed an increase of 1.5-fold compared with the NS without preheating treatment. However, both cases showed increased cytotoxicity compared with that of free DOX. Similarly, in vivo tumor inhibition was increased in the preheated NS. Also, there was an $\sim 9$-fold tumor volume decrease with the preheated NS compared with the control, with no apparent body weight decrease (42).

\section{CPPs coupled to NSs for PC}

Considerably less research and NS development have been conducted for PC, providing an important opportunity in this area. Certain CPPs have been tested on PC with some success, similar to BC, due to an observed increase in cell specificity or uptake. The CPP-NSs described below were designed to improve drug therapy, for gene therapy or to couple with other therapies such as electromagnetic field and laser radiation.

Polyarginine-cholesterol CPP $\left(\mathrm{Chol}-\mathrm{R}_{9}\right)$. Cancer-associated fibroblasts (CAFs) are involved in microenvironment remodeling in PC. Therefore, a novel approach was constructed using a CPP-based amphiphilic peptide, $\mathrm{Chol}^{-\mathrm{R}_{9}}$, an siRNA targeting chemokine ligand 12, and anti-human FAP- $\alpha$ for their involvement in cancer metastasis. As a result, there was an in vitro 7-fold increase in CAF uptake compared with that found using free siRNA, while in vivo, tumor weight decreased $53.4 \%(85)$.
Polyarginine, PSA-selective peptide and polyanionic shielding peptides (DGGDGGDGGDGGHSSKYQG-R . $_{8}$. A DSPE-PEG-based nanoliposome was developed with high PC specificity carrying peptides. This NS included polyarginine CPP and the PSA-selective peptide (HSSKYQ), which possess a cleavable moiety by PSA to enhance further specificity towards PC cells. The anticancer agent was an siRNA targeting polo-like kinase 1. Two cell lines were evaluated, 22Rv1 and PC-3. The latter was used as the control since it is PSA negative. In vivo results showed a $54 \%$ increase in apoptosis and a 5-fold tumor volume decrease (86).

Poly arginine $\left(R_{11}\right)$. Among the CPPs used in PC, the prolinerich sequence $R_{11}$ has shown a high-efficiency uptake in PC cell lines coupled to therapeutic systems (87), making it a promising strategy. The $\mathrm{R}_{11} \mathrm{CPP}$ and the anticancer agent tumor suppressor MIR145 were coupled in a polyethyleneimine polymeric NS to increase the blood circulating time by protecting against the host immune system. In vitro cell uptake was increased from 5.2 to $87.5 \%$, while in vivo NS accumulation in the tumor increased 3.5-fold compared in both cases with free miRNA. Tumor size was decreased 7.5-fold, increasing the mouse lifespan up to 18 weeks (88).

CendR motifpeptide (CRGDK). Another NS with a PC-specific CPP was developed with the CRGDK peptide targeting neuropilin-1 (Nrp-1) in glutathione-functionalized gold NPs, along with platinum IV as an anticancer agent. The NS was tested in PC-3 (Nrp-1 positive) and DU145 (Nrp-1 negative) cell lines. Cell uptake and in vitro cytotoxicity were increased 4- and 28.13-fold, respectively (89).

Polyarginine $\left(R_{11}\right)$. An NS of iron oxide NPs, poly lacticco-glycolic acid $\left(\mathrm{R}_{11}-\mathrm{Mn}\right.$-PGLA), polyarginine CPP and the radio-sensitizer 8-dibenzothiophen-4-yl-2-morpholin-4yl-chromen-4-one was tested in PC-3 and PZ-HPV-7 cells. Results showed the uptake of the NS by the PC3 cells in a dose-dependent manner. However, the $\mathrm{R}_{11} \mathrm{CPP}$ increased cell uptake when an electromagnetic field was applied (90). Using a similar approach, $\mathrm{R}_{11} \mathrm{CPP}$ was used to develop a NS consisting of iron oxide NP coated with poly( $\mathrm{N}$-isopropylacrylamideacrylamide-allylamine) (PMNPs). The $\mathrm{R}_{11}$-PMNPs were biocompatible with normal cells up to $500 \mu \mathrm{g} / \mathrm{ml}$. In vitro cell uptake for PC3 and LNCaP cell lines was higher when PMNPs carried $\mathrm{R}_{11}$. In vivo, tumor $\mathrm{R}_{11}$-PMNPs accumulation was higher than that of normal tissue (91).

Chimeric peptide $\left(\right.$ Ste $\left.-R_{6} L_{2}\right)$. Tripterine is a bioactive compound from Tripterygium wilfordii that is used in traditional Chinese medicine. Nanostructured lipid carriers coated with Ste- $\mathrm{R}_{6} \mathrm{~L}_{2} \mathrm{CPP}$ and loaded with tripterine were designed for targeting PC-3 cell lines. The $\mathrm{IC}_{50}$ reported was decreased from $0.88 \pm 0.08$ to $0.55 \pm 0.07 \mu \mathrm{g} / \mathrm{ml}$, while in vitro apoptosis increased from 0.71 to $14.15 \%$. In vivo, tumor volume was decreased by $57.2 \%$, while the tumor inhibition rate increased 1.96 -fold to $72.68 \pm 6.7 \%$ (92).

Chimeric TAT-bombesin peptide ( ${ }^{99} \mathrm{mTc}$-N2S2-Tat(49-57)$L y_{s 3}$-bombesin). The gastrin-releasing peptide receptor (GRP-r) is overexpressed in PC. Bombesin, a 14-amino acid 


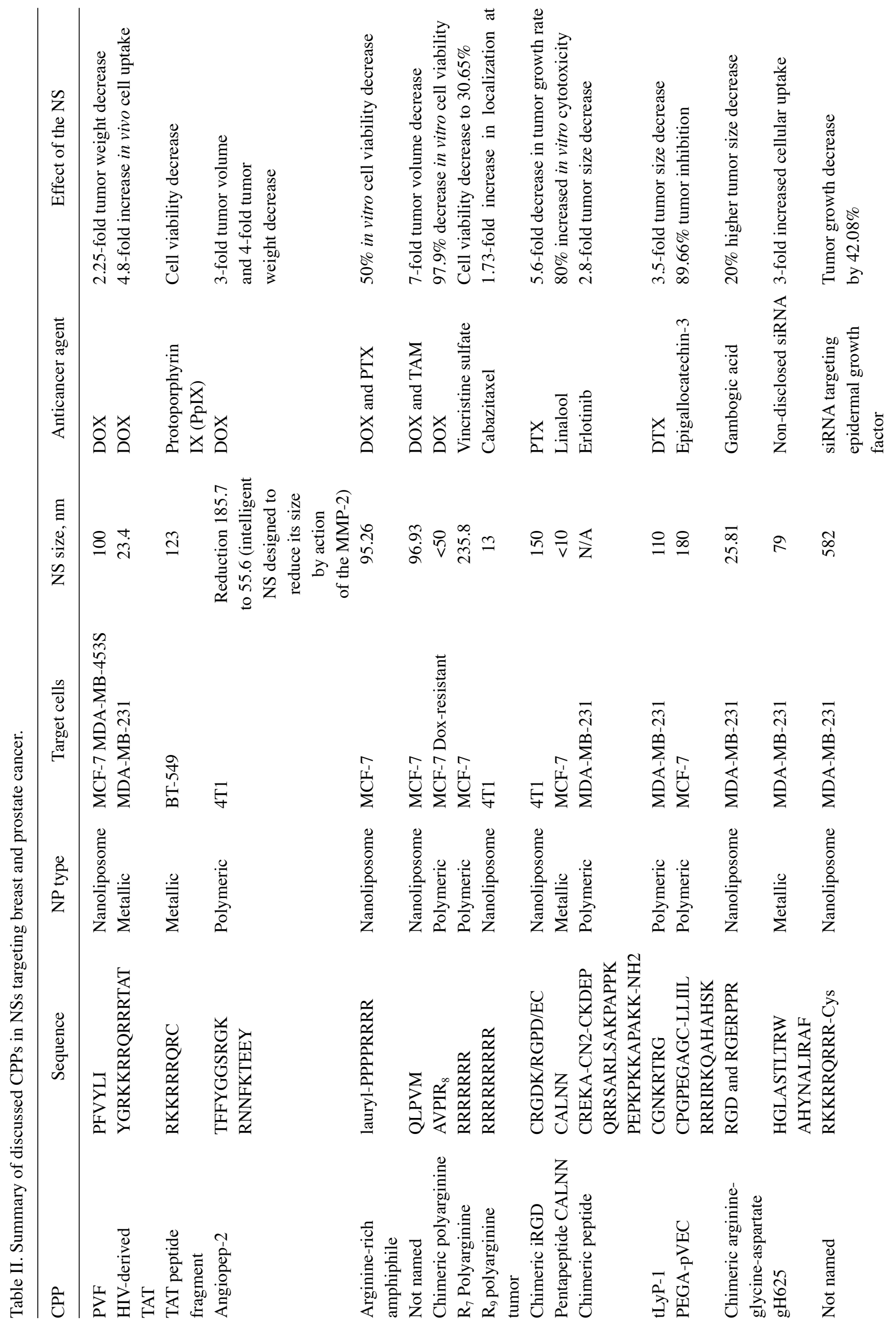




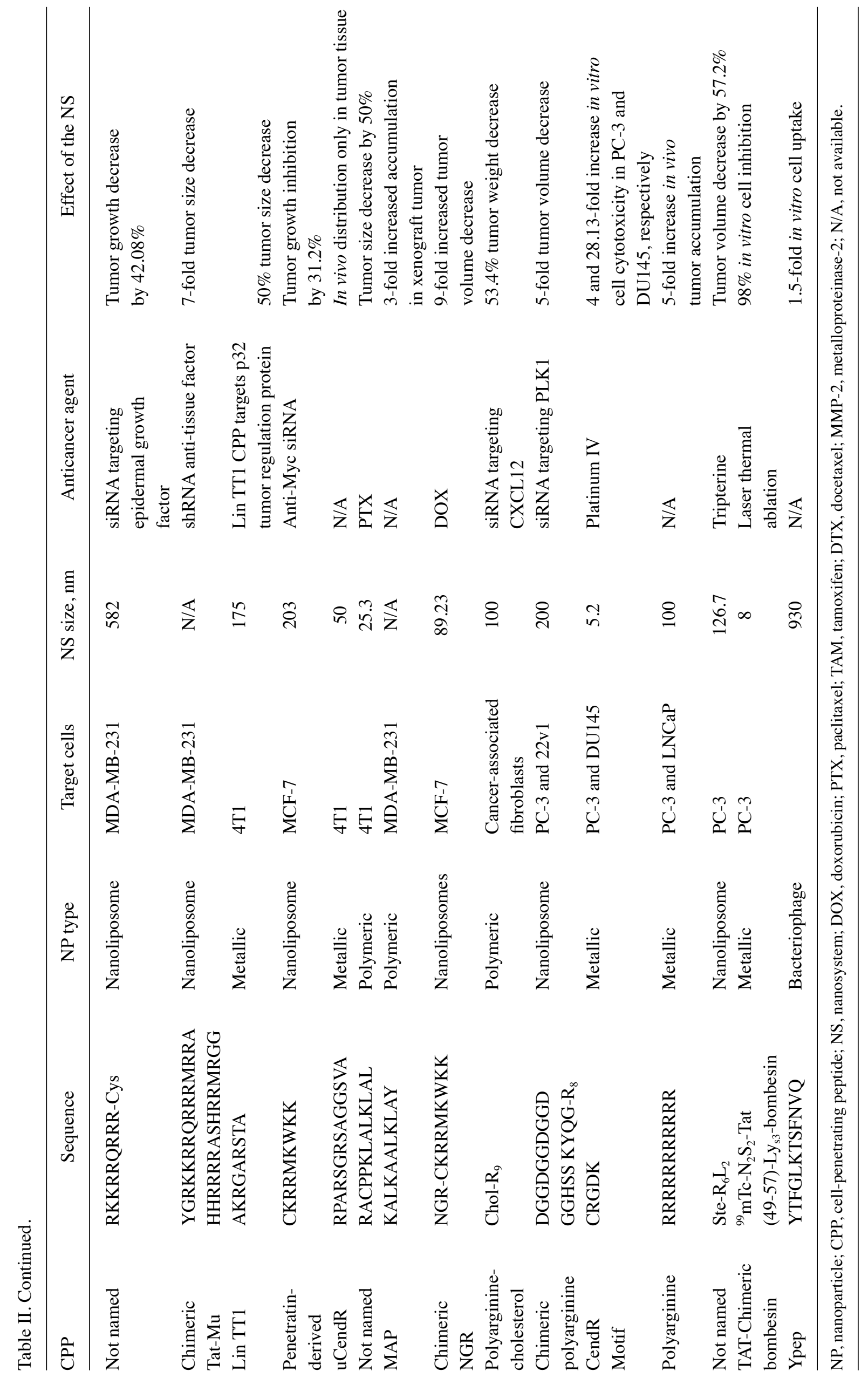


peptide, strongly binds to GRP-r. For this reason, an NS consisting of bombesin and TAT CPP was coupled with gold NPs for PC-specific targeting. The NS also carried radiopharmaceuticals ${ }^{99} \mathrm{mTc}$ and ${ }^{177} \mathrm{Lu}$. Laser thermal ablation was performed as an anticancer treatment. In vitro cell uptake was increased $52.5 \%$ compared with that of the control in the PC-3 cell line. Once the cells were laser-irradiated, cell inhibition was $98.64 \pm 0.4 \%(93)$.

Ypep CPP (YTFGLKTSFNVQ). Bacteriophages have also been studied as NSs for the treatment of PC. The M13 bacteriophage was engineered to express the Ypep CPP targeting PC-3 cells. As a result, in vitro, cell uptake increased $\sim 1.5$-fold, with nearly $100 \%$ cytotoxicity. Unfortunately, no in vivo assays were performed, which could increase the therapeutic potential of this approach. However, the size of the phage could be an important limiting factor, since it had a width of $6 \mathrm{~nm}$ and a length of $930 \mathrm{~nm}$ (94).

\section{Conclusions and outlook}

The present review described NSs coupled to CPPs as guidance tools towards BC and PC cells and tumors. These NSs increased their specificity against cancer cells and tumors, leading to less cytotoxicity against healthy tissue. A summary of the components of the NSs discussed in this article and the effect they have on cancer cells and/or tumors can be found in Table II. One of the most relevant achievements of several of these NSs is a decrease in the anticancer drug used. This decrease, coupled with increased specificity, could lower the risk of adverse effects in patients. Several advantages and disadvantages should be considered to increase the specificity for the NS in order to reach clinical application consistently.

Assays evaluating the efficiency in cell uptake and drug delivery of each type of CPP could provide knowledge and insight on this topic. In addition, the proposed assays could be particularly useful for upcoming scientists developing different NSs that target BC or PC to increase reproducibility and as a baseline to compare their results.

Besides specificity and safety, NS design should consider production costs, development time and processing time. A cost-benefit analysis should be established to compare the specificity needs while keeping complexity at manageable levels. CPPs significantly improved the delivery of anticancer agents towards cancer cells while showing little effect on healthy tissue both on in vitro and in vivo assays. Cell uptake is one of the major contributions to the success of NSs in anticancer therapy. Still, several concerns exist with nanomedicine, with the main issue being the clearance of the NPs from the system once their therapeutic potential has been achieved. Further studies and clinical trials should provide a better understanding of the mechanisms involved in developing NS therapy for both $\mathrm{PC}$ and $\mathrm{BC}$.

\section{Acknowledgements}

The authors would like to thank Dr. Sergio Lozano (Office of the Vice Dean of Research, 'Dr. Jose Eleuterio Gonzalez' University Hospital (Monterrey, Nuevo León, Mexico) for language editing and correcting the original manuscript.

\section{Funding}

The present study was funded by the Consejo NacionaldeCiencia y Tecnología, Call for Basic Scientific Research 2017-2018 (grant no. A1-S-9859).

\section{Availability of data and materials}

Not applicable.

\section{Authors' contributions}

SLG, CNSD and HLGB designed the theme of the review. SLG searched and retrieved the relevant literature and wrote the first draft. CNSD and HLGB reviewed and suggested corrections. All authors have read and approved the final manuscript. Data authentication is not applicable.

\section{Ethics approval and consent to participate}

Not applicable.

\section{Patient consent for publication}

Not applicable.

\section{Competing interests}

The authors declare that they have no competing interests.

\section{References}

1. Bray F, Ferlay J, Soerjomataram I, Siegel RL, Torre LA and Jemal A: Global cancer statistics 2018: GLOBOCAN estimates of incidence and mortality worldwide for 36 cancers in 185 countries. CA Cancer J Clin 68: 394-424, 2018.

2. Hanahan D and Weinberg RA: Hallmarks of cancer: The next generation. Cell 144: 646-674, 2011.

3. Parsa Y, Mirmalek SA, Kani FE, Aidun A, Salimi-Tabatabaee SA Yadollah-Damavandi S, Jangholi E, Parsa T and Shahverdi E: A review of the clinical implications of breast cancer biology. Electron Physician 8: 2416-2424, 2016.

4. Wu D, Si M, Xue HY and Wong HL: Nanomedicine applications in the treatment of breast cancer: Current state of the art. Int J Nanomedicine 12: 5879-5892, 2017.

5. Logothetis CJ, Gallick GE, Maity SN, Kim J, Aparicio A, Efstathiou E and Lin SH: Molecular classification of prostate cancer progression: Foundation for marker-driven treatment of prostate cancer. Cancer Discov 3: 849-861, 2013.

6. Zhang A, Zhang J, Plymate S and Mostaghel EA: Classical and Non-classical roles for pre-receptor control of DHT metabolism in prostate cancer progression. Horm Cancer 7: 104-113, 2016.

7. Liu LL, Xie N, Sun S, Plymate S, Mostaghel E and Dong X: Mechanisms of the androgen receptor splicing in prostate cancer cells. Oncogene 33: 3140-3150, 2014.

8. Culig Z and Santer FR: Androgen receptor signaling in prostate cancer. Cancer Metastasis Rev 33: 413-427, 2014.

9. Rebello RJ, Pearson RB, Hannan RD and Furic L: Therapeutic approaches targeting MYC-Driven prostate cancer. Genes (Basel) 8: 71, 2017.

10. Blee AM, He Y, Yang Y, Ye Z, Yan Y, Pan Y, Dugdale J, Kuehn E, Kohli M, Jimenez R, et al: TMPRSS2-ERG controls luminal epithelial lineage and antiandrogen sensitivity in PTEN and TP53-mutated prostate cancer. Clin Cancer Res 24: 4551$4565,2019$.

11. Nadal M, Prekovic S, Gallastegui N, Helsen C, Abella M, Zielinska K, Gay M, Vilaseca M, Taulès M, Houtsmuller AB, et al: Structure of the homodimeric androgen receptor ligand-binding domain. Nat Commun 8: 14388, 2017. 
12. Damyanov CA, Maslev IK and Pavlov VS: Conventional treatment of cancer realities and problems. Ann Complement Altern Med 1: 1-9, 2018.

13. Schaue D and Mcbride WH: Opportunities and challenges of radiotherapy for treating cancer. Nat Rev Clin Oncol 12: 527-540, 2015.

14. Estanqueiro M, Amaral MH, Conceição J and Sousa Lobo JM: Nanotechnological carriers for cancer chemotherapy: The state of the art. Colloids Surfaces B Biointerfaces 126: 631-648, 2015

15. Vanneman M and Dranoff G: Combining immunotherapy and targeted therapies in cancer treatment. Nat Rev Cancer 12 237-251, 2012

16. Gao QX, Zhou GX, Lin SJ, Paus R and Yue ZC: How chemotherapy and radiotherapy damage the tissue: Comparative biology lessons from feather and hair models. Exp Dermatol 28: 413-418, 2019.

17. Shi J, Kantoff PW, Wooster R and Farokhzad OC: Cancer nanomedicine: Progress, challenges and opportunities. Nat Rev Cancer 17: 20-37, 2017

18. Hayashi K, Ono K, Suzuki H, Sawada M, Moriya M, Sakamoto W and Yogo T: High-frequency, magnetic-field-responsive drug release from magnetic nanoparticle/organic hybrid based on hyperthermic effect. ACS Appl Mater Interfaces 2: 1903-1911, 2010.

19. Kong SD, Zhang W, Lee JH, Brammer K, Lal R, Karin M and Jin S: Magnetically vectored nanocapsules for tumor penetration and remotely switchable on-demand drug release. Nano Lett 10 : 5088-5092, 2010.

20. Tang B, Zaro JL, Shen Y, Chen Q, Yu Y, Sun P, Wang Y, Shen WC, Tu J and Sun C: Acid-sensitive hybrid polymeric micelles containing a reversibly activatable cell-penetrating peptide for tumor-specific cytoplasm targeting. J Control Release 279: 147-156, 2018.

21. Liu Q, Song L, Chen S, Gao J, Zhao P and Du J: A superparamagnetic polymersome with extremely high $\mathrm{T} 2$ relaxivity for MRI and cancer-targeted drug delivery. Biomaterials 114: 23-33, 2017.

22. Ke W, Li J, Mohammed F, Wang Y, Tou K, Liu X, Wen P, Kinoh $\mathrm{H}$, Anraku Y, Chen $\mathrm{H}$, et al: Therapeutic polymersome nanoreactors with tumor-specific activable cascade reactions for cooperative cancer therapy. ACS Nano 13: 2357-2369, 2019.

23. Gao X, Wang S, Wang BL, Deng S, Liu X, Zhang XN, Luo LL, Fan RR, Xiang ML, You C, et al: Improving the anti-ovarian cancer activity of docetaxel with biodegradable self-assembly micelles through various evaluations. Biomaterials 53: 646-658, 2015.

24. Mao HL, Qian F, Li S, Shen JW, Ye CK, Hua L, Zhang LZ, Wu DM, Lu J, Yu RT, et al: Delivery of doxorubicin from hyaluronic acid-modified glutathione-responsive ferrocene micelles for combination cancer therapy. Mol Pharm 16: 987-994, 2019.

25. Li Z, Tan S, Li S, Shen Q and Wang K: Cancer drug delivery in the nano era: An overview and perspectives (Review). Oncol Rep 38: 611-624, 2017.

26. Zariwala MG, Bendre H, Markiv A, Farnaud S, Renshaw D, Taylor KM and Somavarapu S: Hydrophobically modified chitosan nanoliposomes for intestinal drug delivery. Int J Nanomedicine 13: 5837-5848, 2018.

27. Hu Y, Liu X, Cai Z, Zhang H, Gao H, He W, Wu P, Cai C, Zhu JJ and Yan Z: Enhancing the plasmon resonance absorption of multibranched gold nanoparticles in the near-infrared region for photothermal cancer therapy: Theoretical predictions and experimental verification. Chem Mater 31: 471-482, 2019.

28. Bellassai N, D'Agata R, Jungbluth V and Spoto G: Surface plasmon resonance for biomarker detection: Advances in Non-invasive cancer diagnosis. Front Chem 7: 570, 2019.

29. Kishimoto TK, Ferrari JD, Lamothe RA, Kolte PN, Griset AP, O'Neil C, Chan V, Browning E, Chalishazar A, Kuhlman W, et al: Improving the efficacy and safety of biologic drugs with tolerogenic nanoparticles. Nat Nanotechnol 11: 890-899, 2016.

30. Böhmová E, Machová D, Pechar M, Pola R, Venclíková K, Janoušková O and Etrych T: Cell-penetrating peptides: A useful tool for the delivery of various cargoes into cells. Physiol Res 67 (Suppl 2): S267-S279, 2018

31. Kauffman WB, Fuselier T, He J and Wimley WC: Mechanism matters: A taxonomy of cell penetrating peptides. Trends Biochem Sci 40: 749-764, 2015.

32. Frankel AD and Pabo CO: Cellular uptake of the tat protein from human immunodeficiency virus. Cell 55: 1189-1193, 1988.

33. Green M and Loewenstein PM: Autonomous functional domains of chemically synthesized human immunodeficiency virus tat trans-activator protein. Cell 55: 1179-1188, 1988

34. Bechara C and Sagan S: Cell-penetrating peptides: 20 years later, where do we stand? FEBS Lett 587: 1693-1702, 2013.
35. Guidotti G, Brambilla L and Rossi D: Cell-penetrating peptides: From basic research to clinics. Trends Pharmacol Sci 38: 406-424, 2017

36. Huang K and García AE: Free energy of translocating an arginine-rich cell-penetrating peptide across a lipid bilayer suggests pore formation. Biophys J 104: 412-420, 2013.

37. Herce HD, Garcia AE, Litt J, Kane RS, Martin P, Enrique N, Rebolledo A and Milesi V: Arginine-rich peptides destabilize the plasma membrane, consistent with a pore formation translocation mechanism of cell-penetrating peptides. Biophys J 97: 1917-1925, 2009.

38. Islam MZ, Ariyama H, Alam JM and Yamazaki M: Entry of cell-penetrating peptide transportan 10 into a single vesicle by translocating across lipid membrane and its induced pores. Biochemistry 53: 386-396, 2014.

39. Sharmin S, Islam MZ, Karal MAS, Alam Shibly SU, Dohra H and Yamazaki M: Effects of lipid composition on the entry of cell-penetrating peptide oligoarginine into single vesicles. Biochemistry 55: 4154-4165, 2016.

40. Lindgren $\mathrm{M}$ and Langel $\mathrm{U}$ : Classes and prediction of cell-penetrating peptides. In: Methods in molec8ular biology (Clifton, N.J.). Vol 683, pp3-19, 2011.

41. Cai D, Gao W, He B, Dai W, Zhang H, Wang X, Wang J, Zhang X and Zhang Q: Hydrophobic penetrating peptide PFVYLImodified stealth liposomes for doxorubicin delivery in breast cancer therapy. Biomaterials 35: 2283-2294, 2014.

42. Yang Y, Yang Y, Xie X, Cai X, Zhang H, Gong W, Wang Z and Mei X: PEGylated liposomes with NGR ligand and heatactivable cell-penetrating peptide-doxorubicin conjugate for tumor-specific therapy. Biomaterials 35: 4368-4381, 2014.

43. Morshed RA, Muroski ME, Dai Q, Wegscheid ML, Auffinger B, Yu D, Han Y, Zhang L, Wu M, Cheng Y and Lesniak MS: Cellpenetrating peptide-modified gold nanoparticles for the delivery of doxorubicin to brain metastatic breast cancer. Mol Pharm 13: $1843-1854,2016$

44. Zhu X, Xu Y, Solis LM, Tao W, Wang L, Behrens C, Xu X, Zhao L, Liu D, Wu J, et al: Long-circulating siRNA nanoparticles for validating Prohibitin1-targeted non-small cell lung cancer treatment. Proc Natl Acad Sci 112: 7779-7784, 2015.

45. Parvani JG, Gujrati MD, Mack MA, Schiemann WP and Lu ZR: Silencing $\beta 3$ integrin by targeted ECO/siRNA nanoparticles inhibits EMT and metastasis of triple-negative breast cancer. Cancer Res 75: 2316-2325, 2015.

46. Vaidya AM, Sun Z, Ayat N, Schilb A, Liu X, Jiang H, Sun D, Scheidt J, Qian V, He S, et al: Systemic delivery of tumortargeting siRNA Nanoparticles against an oncogenic LncRNA facilitates effective triple-negative breast cancer therapy. Bioconjug Chem 30: 907-919, 2019.

47. Pasut G, Paolino D, Celia C, Mero A, Joseph AS, Wolfram J, Cosco D, Schiavon O, Shen H and Fresta M: Polyethylene glycol (PEG)-dendron phospholipids as innovative constructs for the preparation of super stealth liposomes for anticancer therapy. J Control Release 199: 106-113, 2015.

48. Nag M, Gajbhiye V, Kesharwani P and Jain NK: Transferrin functionalized chitosan-PEG nanoparticles for targeted delivery of paclitaxel to cancer cells. Colloids Surfaces B Biointerfaces 148: 363-370, 2016

49. Ebbesen MF, Olesen MTJ, Gjelstrup MC, Pakula MM, Larsen EKU, Hansen IM, Hansen PL, Mollenhauer J, Malle BM and Howard KA: Tunable CD44-specific cellular retargeting with hyaluronic acid nanoshells. Pharm Res 32: 1462-1474, 2015.

50. Zhong L, Xu L, Liu Y, Li Q, Zhao D, Li Z, Zhang H, Zhang H, Kan Q, Wang Y, et al: Transformative hyaluronic acid-based active targeting supramolecular nanoplatform improves long circulation and enhances cellular uptake in cancer therapy. Acta Pharm Sin B 9: 397-409, 2019.

51. Ben Djemaa S, David S, Hervé-Aubert K, Falanga A, Galdiero S Allard-Vannier E, Chourpa I and Munnier E: Formulation and in vitro evaluation of a siRNA delivery nanosystem decorated with gH625 peptide for triple negative breast cancer theranosis. Eur J Pharm Biopharm 131: 99-108, 2018.

52. Mäe M, Myrberg H, El-Andaloussi S and Langel Ü: Design of a tumor homing cell-penetrating peptide for drug delivery. Int J Pept Res Ther 15: 11-15, 2009.

53. Lim KJ, Sung BH, Shin JR, Lee YW, Kim DJ, Yang KS and Kim SC: A cancer specific cell-penetrating peptide, BR2, for the efficient delivery of an $\mathrm{scFv}$ into cancer cells. PLoS One 8: e66084, 2013

54. Fang SL, Fan TC, Fu HW, Chen CJ, Hwang CS, Hung TJ, Lin LY and Chang MD: A novel cell-penetrating peptide derived from human eosinophil cationic protein. PLoS One 8: e57318, 2013. 
55. Kalyanaraman B: Teaching the basics of the mechanism of doxorubicin-induced cardiotoxicity: Have we been barking up the wrong tree? Redox Biol 29: 101394, 2020.

56. Fales AM, Yuan H and Vo-Dinh T: Cell-penetrating peptide enhanced intracellular Raman imaging and photodynamic therapy. Mol Pharm 10: 2291-2298, 2013.

57. Hossain MK, Cho HY, Kim KJ and Choi JW: In situ monitoring of doxorubicin release from biohybrid nanoparticles modified with antibody and cell-penetrating peptides in breast cancer cells using surface-enhanced Raman spectroscopy. Biosens Bioelectron 71: 300-305, 2015.

58. Wan Y, Dai W, Nevagi RJ, Toth I and Moyle PM: Multifunctional peptide-lipid nanocomplexes for efficient targeted delivery of DNA and siRNA into breast cancer cells. Acta Biomater 59: 257-268, 2017.

59. Hu G, Chun X, Wang Y, He Q and Gao H: Peptide mediated active targeting and intelligent particle size reduction-mediated enhanced penetrating of fabricated nanoparticles for triple-negative breast cancer treatment. Oncotarget 6: 41258-41274, 2015.

60. Sardan M, Kilinc M, Genc R, Tekinay AB and Guler MO: Cell penetrating peptide amphiphile integrated liposomal systems for enhanced delivery of anticancer drugs to tumor cells. Faraday Discuss 166: 269-283, 2013.

61. Wang X, Chen X, Yang X, Gao W, He B, Dai W, Zhang H Wang X, Wang J, Zhang X, et al: A nanomedicine based combination therapy based on QLPVM peptide functionalized liposomal tamoxifen and doxorubicin against Luminal A breast cancer. Nanomedicine 12: 387-397, 2016.

62. Wang H, Wang H, Liang J, Jiang Y, Guo Q, Peng H, Xu Q and Huang Y: Cell-penetrating apoptotic peptide/p53 DNA nanocomplex as adjuvant therapy for drug-resistant breast cancer. Mol Pharm 11: 3352-3360, 2014

63. Chen J, Li S and Shen Q: Folic acid and cell-penetrating peptide conjugated PLGA-PEG bifunctional nanoparticles for vincristine sulfate delivery. Eur J Pharm Sci 47: 430-443, 2012

64. Hu H, Wang J, Wang H, Tan T, Li J, Wang Z, Sun K, Li Y and Zhang Z: Cell-penetrating peptide-based nanovehicles potentiate lymph metastasis targeting and deep penetration for anti-metastasis therapy. Theranostics 8: 3597-3610, 2018.

65. Cabral H, Makino J, Matsumoto Y, Mi P, Wu H, Nomoto T, Toh K, Yamada N, Higuchi Y, Konishi S, et al: Systemic targeting of lymph node metastasis through the blood vascular system by using size-controlled nanocarriers. ACS Nano 9: 4957-4967, 2015.

66. Kang S, Ahn S, Lee J, Kim JY, Choi M, Gujrati V, Kim H, Kim J, Shin EC and Jon S: Effects of gold nanoparticle-based vaccine size on lymph node delivery and cytotoxic T-lymphocyte responses. J Control Release 256: 56-67, 2017.

67. Su J, Sun H, Meng Q, Yin Q, Tang S, Zhang P, Chen Y, Zhang Z, $\mathrm{Yu} \mathrm{H}$ and $\mathrm{Li}$ Y: Long circulation red-blood-cell-mimetic nanoparticles with peptide-enhanced tumor penetration for simultaneously inhibiting growth and lung metastasis of breast cancer. Adv Funct Mater 26: 1243-1252, 2016.

68. Hamilton AM, Aidoudi-Ahmed S, Sharma S, Kotamraju VR, Foster PJ, Sugahara KN, Ruoslahti E and Rutt BK: Nanoparticles coated with the tumor-penetrating peptide iRGD reduce experimental breast cancer metastasis in the brain. J Mol Med 93. 991-1001, 2015.

69. Jabir MS, Taha AA, Sahib UI, Taqi ZJ, Al-Shammari AM and Salman AS: Novel of nano delivery system for Linalool loaded on gold nanoparticles conjugated with CALNN peptide for application in drug uptake and induction of cell death on breast cancer cell line. Mater Sci Eng C Mater Biol Appl 94: 949-964, 2019.

70. Wan X, Liu C, Lin Y, Fu J, Lu G and Lu Z: pH sensitive peptide functionalized nanoparticles for co-delivery of erlotinib and DAPT to restrict the progress of triple negative breast cancer Drug Deliv 26: 470-480, 2019

71. Liang DS, Su HT, Liu YJ, Wang AT and Qi XR: Tumorspecific penetrating peptides-functionalized hyaluronic acid-d- $\alpha$-tocopheryl succinate based nanoparticles for multi-task delivery to invasive cancers. Biomaterials 71: 11-23, 2015.

72. Ding J, Yao J, Xue J, Li R, Bao B, Jiang L, Zhu JJ and He Z: Tumor-homing Cell-penetrating peptide linked to colloidal mesoporous silica Encapsulated (-)-Epigallocatechin-3-gallate as drug delivery system for breast cancer therapy in vivo. ACS Appl Mater Interfaces 7: 18145-18155, 2015.

73. Ding J, Liang T, Zhou Y, He Z, Min Q, Jiang L and Zhu J: Hyaluronidase-triggered anticancer drug and siRNA delivery from cascaded targeting nanoparticles for drug-resistant breast cancer therapy. Nano Res 10: 690-703, 2016.

74. Ding J, Liang T, Min Q, Jiang L and Zhu JJ: 'Stealth and FullyLaden' Drug carriers: Self-assembled nanogels encapsulated with epigallocatechin gallate and siRNA for drug-resistant breast cancer therapy. ACS Appl Mater Interfaces 10: 9938-9948, 2018.
75. Huang R, Li J, Kebebe D, Wu Y, Zhang B and Liu Z: Cell penetrating peptides functionalized gambogic acid-nanostructured lipid carrier for cancer treatment. Drug Deliv 25: 757-765, 2018.

76. Perillo E, Hervé-Aubert K, Allard-Vannier E, Falanga A, Galdiero S and Chourpa I: Synthesis and in vitro evaluation of fluorescent and magnetic nanoparticles functionalized with a cell penetrating peptide for cancer theranosis. J Colloid Interface Sci 499: 209-217, 2017.

77. Cao H, Zou L, He B, Zeng L, Huang Y, Yu H, Zhang P, Yin Q, Zhang Z and Li Y: Albumin biomimetic nanocorona improves tumor targeting and penetration for synergistic therapy of metastatic breast cancer. Adv Funct Mater 27: 1605679, 2017.

78. Jing H, Cheng W, Li S, Wu B, Leng X, Xu S and Tian J: Novel cell-penetrating peptide-loaded nanobubbles synergized with ultrasound irradiation enhance EGFR siRNA delivery for triple negative Breast cancer therapy. Colloids Surfaces B Biointerfaces 146: 387-395, 2016.

79. Govindarajan S, Sivakumar J, Garimidi P, Rangaraj N, Kumar JM, Rao NM and Gopal V: Targeting human epidermal growth factor receptor 2 by a cell-penetrating peptide-affibody bioconjugate. Biomaterials 33: 2570-2582, 2012.

80. Sharma S, Kotamraju VR, Mölder T, Tobi A, Teesalu T and Ruoslahti E: Tumor-penetrating nanosystem strongly suppresses breast tumor growth. Nano Lett 17: 1356-1364, 2017.

81. Li G, Gao Y, Gong C, Han Z, Qiang L, Tai Z, Tian J and Gao S: Dual-blockade immune checkpoint for breast cancer treatment based on a tumor-penetrating peptide assembling nanoparticle. ACS Appl Mater Interfaces 11: 39513-39524, 2019.

82. Xie X, Yang Y, Lin W, Liu H, Liu H, Yang Y, Chen Y, Fu X and Deng J: Cell-penetrating peptide-siRNA conjugate loaded YSA-modified nanobubbles for ultrasound triggered siRNA delivery. Colloids Surfaces B Biointerfaces 136: 641-650, 2015.

83. Braun GB, Sugahara KN, Yu OM, Kotamraju VR, Mölder T, Lowy AM, Ruoslahti E and Teesalu T: Urokinase-controlled tumor penetrating peptide. J Control Release 232: 188-195, 2016.

84. Fei L, Yap LP, Conti PS, Shen WC and Zaro JL: Tumor targeting of a cell penetrating peptide by fusing with a $\mathrm{pH}$-sensitive histidineglutamate co-oligopeptide. Biomaterials 35: 4082-4087, 2014.

85. Lang J, Zhao X, Qi Y, Zhang Y, Han X, Ding Y, Guan J, Ji T, Zhao Y and Nie G: Reshaping prostate tumor microenvironment to suppress metastasis via cancer-associated fibroblast inactivation with peptide-assembly-based nanosystem. ACS Nano 13: 12357-12371, 2019

86. Xiang B, Dong DW, Shi NQ, Gao W, Yang ZZ, Cui Y, Cao DY and Qi XR: PSA-responsive and PSMA-mediated multifunctional liposomes for targeted therapy of prostate cancer. Biomaterials 34: 6976-6991, 2013.

87. Zhou J, Fan J and Hsieh JT: Inhibition of mitogen-elicited signal transduction and growth in prostate cancer with a small peptide derived from the functional domain of DOC-2/DAB2 delivered by a unique vehicle. Cancer Res 66: 8954-8958, 2006.

88. Zhang T, Xue X, He D and Hsieh JT: A prostate cancer-targeted polyarginine-disulfide linked PEI nanocarrier for delivery of microRNA. Cancer Lett 365: 156-165, 2015.

89. Kumar A, Huo S, Zhang X, Liu J, Tan A, Li S, Jin S, Xue X, Zhao Y, Ji T, et al: Neuropilin-1-targeted gold nanoparticles enhance therapeutic efficacy of Platinum(IV) drug for prostate cancer treatment. ACS Nano 8: 4205-4220, 2014

90. Menon JU, Tumati V, Hsieh JT, Nguyen KT and Saha D: Polymeric nanoparticles for targeted radiosensitization of prostate cancer cells. J Biomed Mater Res A 103: 1632-1639, 2015.

91. Wadajkar AS, Menon JU, Tsai YS, Gore C, Dobin T, Gandee L, Kangasniemi K, Takahashi M, Manandhar B, Ahn JM, et al: Prostate cancer-specific thermo-responsive polymer-coated iron oxide nanoparticles. Biomaterials 34: 3618-3625, 2013.

92. Yuan L, Liu CY, Chen Y, Zhang ZH, Zhou L and Qu D: Antitumor activity of tripterine via cell-penetrating peptidecoated nanostructured lipid carriers in a prostate cancer model. Int J Nanomedicine 8: 4339-4350, 2013.

93. Jiménez-Mancilla N, Ferro-Flores G, Santos-Cuevas C, OcampoGarcía B, Luna-Gutiérrez M, Azorín-Vega E, Isaac-Olivé K, Camacho-López M and Torres-García E: Multifunctional targeted therapy system based on (99m) Tc/(177) Lu-labeled gold nanoparticles-Tat(49-57)-Lys(3)-bombesin internalized in nuclei of prostate cancer cells. J Label Compd Radiopharm 56: 663-671, 2013.

94. DePorter SM and McNaughton BR: Engineered M13 bacteriophage nanocarriers for intracellular delivery of exogenous proteins to human prostate cancer cells. Bioconjug Chem 25: 1620-1625, 2014.

This work is licensed under a Creative Commons Attribution-NonCommercial-NoDerivatives 4.0 International (CC BY-NC-ND 4.0) License. 